\title{
Technical Efficiency of Universities in Telangana State through Data Envelopment Analysis (DEA) Approach
}

\author{
R. Nellutla, R. Ashok, M. Ramesh, and V. V. Haragopal
}

\begin{abstract}
In this present research paper we analyze the universities data by CCR, BCC models through Data Envelopment Analysis (DEA) approach for the State of Telangana. To know the Performance of student's university wise in state of Telangana. University wise Performances is presented along with technical efficiency, Pure Technical Efficiency, Scale Efficiency, CRS, VRS, Reference set and Peers. Measuring the Technical Efficiency (TE) and Pure Technical Efficiency (PTE) of the universities by CCR, BCC Model through DEA approach.
\end{abstract}

Keywords - BCC Model, CCR Model, CRS, DEA, Pure Technical Efficiency, Scale Efficiency, VRS.

\section{INTRODUCTION}

Since decades, many fields are applied data analytics techniques.This applied fields share common concern over design and action on how to improve the data analytics. The concept of best practice is to purposeful achievements in Government sector and even in private sector for their improvements. The most important characteristic is connecting with a "best practice". The best practice is a comparative process, an action and link between an action and outcomes or goals. The researchers [1] applied DEA techniques in school initiative studies. The researchers like Rhodes, Cooper and Thanassoulis was applied appropriate methods for evaluating the efficiencies, which directed their efforts extending towards "best practice" to the field of education. Which led to the lot of improvements in the educational field. Kwimbere [2] used Data Envelopment Analysis Techniques to set of universities in U.K and performed subject wise analysis and also [3] Authors applied different models in DEA for their evaluation process.

In the present research study, evaluate and analyze the performance of Osmania University (O.U), Kakatiya University (K.U), Palamuru University (P.U), Telangana University (T.U), Satavahana University (S.U) and Mahatma Gandhi University (M.G.U) in Telangana state. Which are major public universities in Telangana State. In this research study we evaluate the efficiency of universities and identify which university performance is well for the data gathered for the Academic Year A. Y 2019-2020 by applying CCR model, BCC model and S.E through DEA approach.

\section{DATA ENVELOPMENT ANALYSIS}

The Data Envelopment Analysis is a emerged into a greater application for evaluating the performance of the Decision Making Units. Data Envelopment Analysis (DEA) is a "mathematical programming" approach for evaluating the performance of a set decision making units DMUS. This DMUs converts multiple inputs into Multiple outputs. The DEA Technique is deals with the optimum solution of DecisionMaking Units of identified input, output variables. This DEA signifies a greater development and continuous advancing for the analysis of data, which find broad uses in society, industry, and even in education fields. Authors [4] evaluate the hospital efficiency in India by using DEA.

In this present research study, we consider DEA Technique and which is used to measure the CCR and BCC Models efficiency scores of the Universities in Telangana state. In this study we are consider number of boys and girls appeared in examination at the university level and their results.Authors [5] applied DEA

Published on December 13, 2021.

R. Nellutla, Guru Nanak Institutions Technical Campus(A), Hyderabad, Telangana, India.

(corresponding e-mail: rajunellutla@gmail.com)

R. Ashok, Vishwa Vishwani Institute of Systems and Management, Hyderabad, Telangana, India.

(e-mail: ashokpts@gmail.com)

M. Ramesh, Matrusri Engineering College, Hyderabad, Telangana, India.

(e-mail: rameshmsc2001@gmail.com)

V V Haragopal, Osmania University, Hyderabad \& Director (Al\&ML), AiZen Algo Pvt. Hyderabad, Telangana, India.

( e-mail: haragopal.vajjha@gmail.com) 
techniques and found the important results in Management Schools performance in SSC examinations of state of Andhra Pradesh. Factors to be considered when selecting input and output variables:

- Availability of data;

- Reliable to education;

- Accuracy.

\section{A. Inputs in DEA}

The inputs are measurements units, which factors used to carry out the delivery of the services. Measurement of these factors is important in a fair evaluation process. Authors [6] categorized the inputs of the universities. In this research study we consider inputs as the educational inputs, which units are taken from the university examinations data i.e., the number of boys and number of girls appeared in university end examinations in various public universities in Telangana state.

\section{B. Outputs in DEA}

Educational Outputs indicators measuring the levels of the activities of the services and programs. It is always useful to disclose indicators that provide information about the activity carried out by [7]. The quality is as an attribute that can be affects the user's perception, and the process of input and output relation. It should be considered to access the efficiency of the process. Authors [8] Constructed DEA techniques to Selection and Analysis of Input \& Output Variables using DEA of Decision-Making Units Indian Private Sector Banks. Authors [9] applied CCR model to Agricultural farming data and find useful results for improvement in this region. Authors [10] also performed DEA techniques and identified which districts performance of SSC Examinations in Andhra Pradesh. In this present study we give the educational outputs from the Data collected at the university level i.e., number of boys and girls passed out in university examinations from different universities in Telangana state.

\section{Efficiency Analysis}

The Efficiency is an important factor in economic analysis. This process has a single input and single output. The efficiency is obtained by taking ratio between output and input:

$$
\text { Efficency }=\frac{\text { Output }}{\text { Input }} \ldots
$$

The production process that occurs in educational institutions seems to have the same characteristics of the above economic model. The transformation between inputs and output as shown in the following Fig. 1.

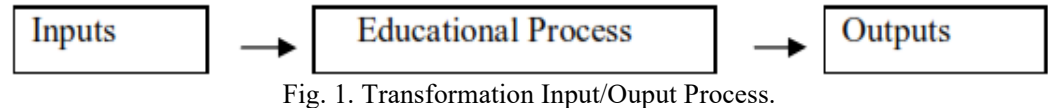

\section{DAta ENVElopment ANAlysis Models}

\section{A. CCR Model}

The Authors [11] and [12] are identified CCR model. Which model is most widely used in Data Envelopment Analysis (DEA). In this model a Constant Return to Scale (CRS) relation assumption is to be used. The first DEA model was developed by Charnes, A, W. Cooper and E. Rhodes (CCR). Authors published about the CCR Model in [12]. The CCR model computes the Technical Efficiency (TE) for each unit in the given data set.

\section{B. Terminology and Notations in CCR Model}

Decision Making Units are $\mathrm{DMU}_{1}, \mathrm{DMU}_{2}, \mathrm{DMU}_{3}, \ldots, \mathrm{DMU}_{\mathrm{n}}$. This DMUs are contain input and output variables.

$$
\begin{gathered}
x_{i j} \text { : The } \mathrm{i}^{\text {th }} \text { input of the jth DMUs } x_{1 j}, x_{2 j}, x_{3 j}, \ldots, x_{m j} . \\
y_{i j} \text { : The } \mathrm{j}^{\mathrm{th}} \text { output of the } \mathrm{jth} \text { DMUs } y_{1 j}, y_{2 j}, y_{3 j}, \ldots, x_{s j} . \\
v_{i} \text { : The weight of the } \mathrm{i}^{\text {th }} \text { input } \mathrm{i}=1,2,3, \ldots, \mathrm{m} . \\
u_{r} \text { : The weight of the } \mathrm{j}^{\text {th }} \text { output } \mathrm{r}=1,2,3, \ldots, \mathrm{s} \text {. }
\end{gathered}
$$

The Fractional Programming Problem (FPP) is as follows:

$$
\text { Maximize } R=\frac{u_{1} y_{1 k}+u_{2} y_{2 k}+\cdots+u_{s} y_{s k}}{v_{1} x_{1 k}+v_{2} x_{2 k}+\cdots+v_{m} x_{m k}}
$$




$$
\begin{aligned}
& \text { Sub. to Constraints } \frac{u_{1} y_{1 j}+u_{2} y_{2 j}+\cdots+u_{s} y_{s j}}{v_{1} x_{1 j}+v_{2} x_{2 j}+\cdots+v_{m} x_{m j}} \leq 1, \forall \mathrm{j}=1,2, \ldots, \mathrm{n} \text {. } \\
& \text { Non negativity } u_{1}, u_{2}, u_{3}, \ldots, u_{s} \geq 0, v_{1}, v_{2}, v_{3}, \ldots v_{m} \geq 0
\end{aligned}
$$

The input and output ratio of every DMU should not be exceed 1. Mathematically equation (4) is not sufficient for the fractional terms in equation (3) become a positive. For this we can replace the Factional Programming Problem (FPP) by following LPP:

$$
\begin{gathered}
\operatorname{Max} R(u, v)=u_{1} y_{1 k}+u_{2} y_{2 k}+u_{3} y_{3 k}---+u_{s} y_{s k} \\
\text { Subject to } v_{1} x_{1 j}+v_{2} x_{2 j}+v_{3} x_{3 j}+---+v_{m} x_{m j}=1 \\
u_{1} y_{1 j}+u_{2} y_{2 j}+u_{3} y_{3 k}+---+u_{s} y_{s j} \leq v_{1} x_{1 j}+v_{2} x_{2 j}+v_{3} x_{3 j}+---+v_{m} x_{m j} \\
u_{1}, u_{2}, u_{3}, \ldots, u_{s} \geq 0, v_{1}, v_{2}, v_{3}, \ldots v_{m} \geq 0
\end{gathered}
$$

The Optimum Solution is $\left(v^{*}, u^{*}, R^{*}\right)$ :

$$
\text { The Reference set } R_{s}=\left\{j: \sum_{r=1}^{s} u_{r}^{*} y_{r j}=\sum_{i=1}^{m} v_{i}^{*} x_{i j} j=1,2,3, \ldots, n\right\}
$$

where $R_{S}$ is a primal problem.

This Primal Problem (PP) becomes:

$$
\begin{gathered}
\operatorname{Max} R^{*}\left(v^{*}, \mathrm{u}^{*}\right)=\sum_{r=1}^{s} u_{r} y_{r k} \\
\text { Subject to constraints: } \sum_{r=1}^{s} u_{r}^{*} y_{r j}-\sum_{i=1}^{m} v_{i}^{*} x_{i j} \leq 0 j=1,2,3, \ldots, n \\
\sum_{i=1}^{m} v_{i} x_{i k}=1 \\
\text { Non negativity } u_{r} \geq 0, v_{i} \geq 0
\end{gathered}
$$

The above LPP produce the Optimum Solution $R^{*}$. This optimal solution efficiency score is known as Technical Efficiency T.E of CCR model. This Technical Efficiency scores were obtained by repeating for each DMU.

The optimal efficiency values of $R^{*} \leq 1$. If optimal value of $R^{*}<1$ shows relatively inefficient and $R^{*}=1$ indicates relatively efficient, having its virtual inputs and outputs combination points on the frontier.

The objectivity of the CCR model is to minimize the input which satisfy atleast the given output level and maximize the output without considerable level of observed input values.

\section{BCC Model}

To the existing model approach CCR extended by Banker, R.D., Charnes R.F and Cooper W.W. This B.C.C Model is next model in DEA. Which is used in efficiency analysis and a variable return to scale (VRS) relationship assumed between input variables and output variables. Banker, Charnes and Cooper (BCC) who first introduced it in [12]. If the total constraints equal to one is adjoined, which is known as Banker, Charnes R.F and Cooper BCC model. Added a constraint as an additional variable into multiplier problem. This extra variable is makes it possible to affect returns to scale VRS evaluation. This scale is constant or decreasing or increasing. This BCC model is also referred to Variable Returns to Scale (VRS) model. The convexity constraints in this model formulation make sure that composite units of similar scale size units being calculated.

Let us consider A, B, C and D are DMUS. Which is have a single input and single output units. 


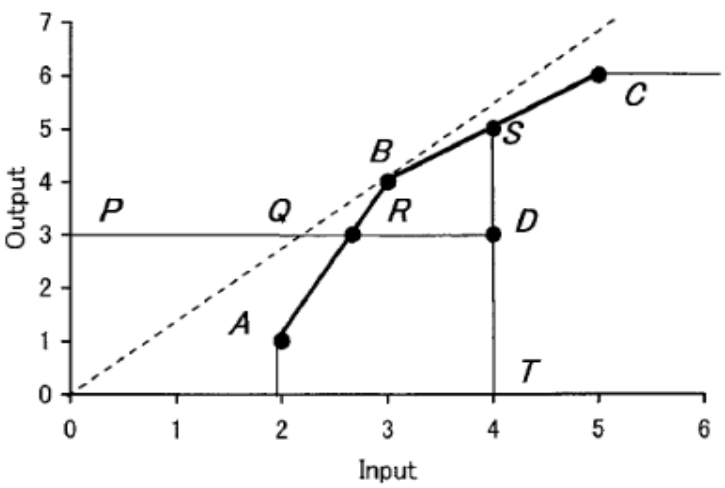

Fig. 2. BCC Model.

From the above Fig. 2 shows that A, B, C, D are four DMUS with single input and output units. The efficient limit of the CCR model is dotted line that can be process through B from the origin and the BCC model consists the bolded lines and connected between A, B and C. The production possibility set area consists of the efficient frontier. From the above figure it is clear that BCC efficient frontiers are A, B and C. The points on the solid lines connected between A \& B, B \& C. However, CCR Model efficient DMU is only B.

The Production Possibility Set (P.P.S) of the BCC Model is defined below:

$$
P(B C C)=\{(x, y) / x \geq X \lambda, y \leq Y \lambda, e \lambda=1, \lambda \geq 0\}
$$

The input-oriented BCC Model calculate the pure technical efficiency of DMUs. By solving envelopment form of linear programming problem:

$$
\begin{aligned}
& \text { Objective function } \operatorname{Min}\left(\theta_{B}, \lambda\right): \theta_{B} \\
& \text { Subject to Constraints: } \theta_{B} x_{0}-X \lambda \geq 0 \\
& \qquad \begin{array}{c}
Y \lambda \geq y_{o} \\
\qquad \lambda=1 \\
\lambda \geq 0
\end{array}
\end{aligned}
$$

Here $\theta_{B}$ is a known as scalar.

Dual multiplier form of the linear programming problem $\left(B C_{R}\right)$ is expressed as:

Objective function:

Subject to Constraints:

$$
\operatorname{Maximize}\left(v, u, x_{0}\right) R=u y_{0}-u_{0}
$$

$$
\begin{gathered}
v x_{0}=1 \\
-v X+u Y-u_{0} e \leq 0 \\
u \geq 0, v \geq 0
\end{gathered}
$$

Here $\mathrm{u}_{0}$ is free in sign.

Here $v \& u$ are Vectors and $\theta \& u_{0}$ are Scalars .

The equivalent BCC Fractional Programming is found from the dual problem as:

$$
\begin{aligned}
& \text { Objective function : Maximize } \frac{u y_{0}-u_{0}}{v x_{0}} \\
& \text { Sub to constraints: } \frac{u y_{j}-u_{0}}{v x_{j}} \leq 1, j=1,2,3, \ldots, n
\end{aligned}
$$

$v \geq 0, u \geq 0, u_{0}$ is free in sign. 
The difference between CCR and BCC model is present in the free variable $u_{0}$, which dual variable associated with the constraint $e \lambda=1$ in the Envelopment model. This evaluation is obtained from the CCR model and BCC model.

The BCC model optimal solution is presented by $\left(\theta_{B}^{*}, \lambda^{*}, s^{-*}, s^{+*}\right)$. Where $\theta_{B}^{*} \lambda^{*} s^{-*}$ and $s^{+*}$ represents maximal Pure Technical Efficiency (PTE), peer weight, input excesses and output short fall respectively.

\section{Potential Improvement (P. I)}

Potential Improvement is the efficiency performance study. This study can be providing the information about which area an inefficient unit needs to improve in order to be efficient. This information can help inefficient unit needs to be improved.

\section{E. Reference Comparison ( $R C$ )}

The amount of units was found inefficient status then it's felt to be justified. This information can be used for setting targets for the inefficient units. The inefficient units should be compared with the units in its reference set (R. S).

\section{F. Peer Groups or Reference Set}

DEA identified the set of efficient units, called the Peer Groups, which includes those units that are efficient if evaluated with the optimal weights of inefficient unit. This Peer Group made up of DMUs are characterized by operating methods similar to the inefficient unit being examined, which is the realistic term of comparison. This unit main aim is to be imitate in order to improve its performance level. This peer group is also known as reference set.

\section{G. Ranks of DMUS}

In Data Eveloment Analysis (DEA) identify and assign a ranks of a DMUS based on the reference set.

\section{H. Returns to Scale}

The performance evaluations depend on Returns to Scale (RTS). There are two types of returns to scale techniques used in DEA. Those are Constant Returns to Scale and Variable returns to scale.

\section{Constant Returns to Scale}

This technology under consideration is such that an increase in all the inputs by same proportion results in an increase in all the outputs by the same proportion is known as Constant Returns to Scale (CRS).

\section{J. Variable Returns to Scale}

The variable returns to scale (VRS) result in a non- proportionate change either increase or decrease in the outputs. If non- proportionate change increase in the outputs is known as Increasing returns to scale IRS and non- proportionate change decreases in the outputs is known as decreasing returns to scale DRS.

The difference between the input-reducing and the output-increasing measures are illustrated in following figures by consider the DMUS A, B, C\&D.

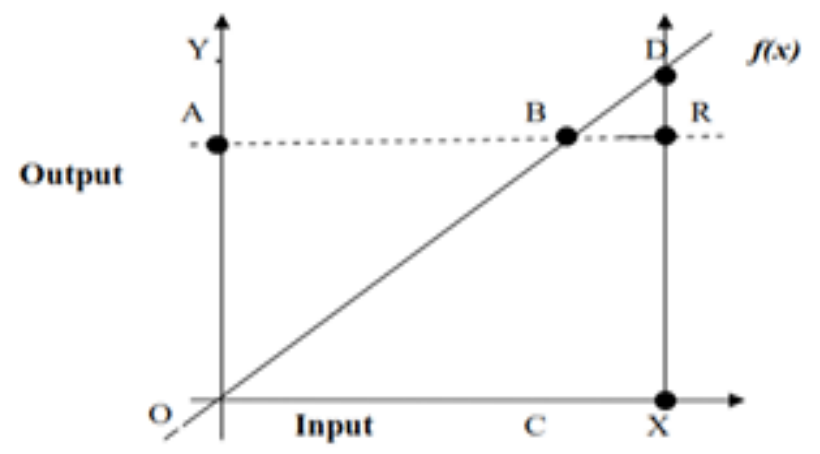

Fig.3. Constant Returns to Scale.

From the Fig. 3 it is clear that the production of a single output is examine graphically. From Fig. 3 we observe that $\mathrm{f}(\boldsymbol{x})$ is a straight line and has a single slope. Every unit is increases in input that goes into the process, the output produced increases by a constant proportional quantity; hence it is represented by Constant Returns to Scale (CRS).

In Fig. 3 we observe that $\mathrm{R}$ is projected onto the frontier either under an input- reducing or an output increasing consideration. By comparison $\mathrm{B}$ and $\mathrm{D}$ points are projected on the frontier.

In Fig. 4, the function $\boldsymbol{f}(\boldsymbol{x})$ has an increasing slope. For every unit increases in input and the output increases by a more than proportionate quantity displays increasing returns to scale. Which represents the increasing returns to scale IRS. 


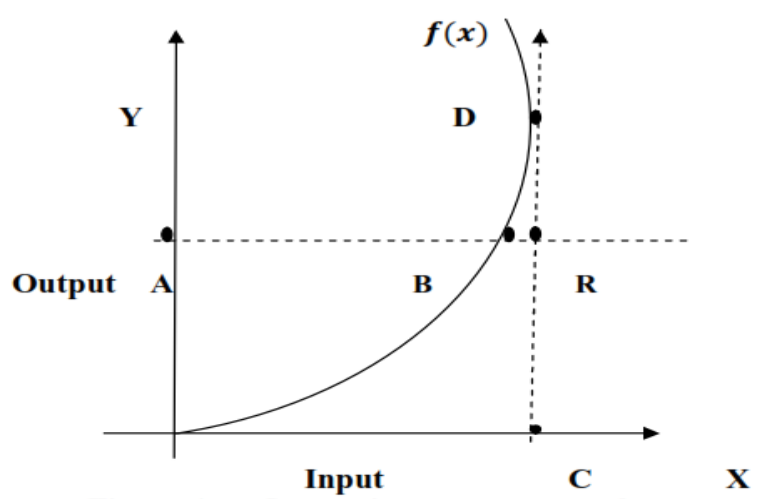

Fig. 4. Increasing returns to scale.

In Fig. 5, the function $\boldsymbol{f}(\boldsymbol{x})$ has a decreasing slope. For every unit decreases in input and the output decreases by a more than proportionate quantity displays decreasing returns to scale (DRS). It is clear that $\mathrm{R}$ is lies below the efficient status. For this, $\mathrm{R}$ could be projected onto the frontier either under an inputreducing or an output-increasing consideration. Where $\mathrm{B}$ and $\mathrm{D}$ points are projected on the frontier. The input reducing efficiency is obtained by $\frac{C R}{C D}$.

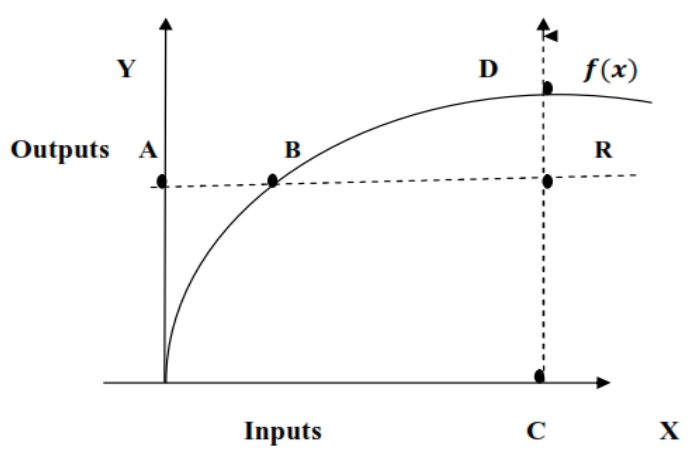

Fig. 5. Decreasing returns to scale.

\section{K. Most Productive Scale Size (MPSS)}

The CCR and BCC models are used to find which DMU is under Most Productive Scale Size. A Decision-Making Units found to be efficient in a CCR Model will also found an efficient DMU in BCC model and constant returns to scale (CRS) prevails.

\section{Choosing OF InPut OUtPut VARIABLES AND DATA ANALYSIS}

In this present research university wise student's results data was chosen for the Academic Year A .Y 2019-2020 and measuring the performance of the public universities in Telangana state. The input and output variables selection is presented in the following table.

\begin{tabular}{cc} 
TABLE I: INPUTS AND OUTPUTS CONSIDERED FOR THE STUDY \\
\hline \hline Name & Name of the variables \\
\hline \multirow{2}{*}{ Inputs } & No. of boys appeared \\
& No. of girls appeared \\
Outputs & No. of boys passed out \\
& No. of girls passed out \\
\hline \hline
\end{tabular}

University wise CCR model scores, references, rank and peers for the A.Y 2019-2020 is presented below:

TABLE II: THE CCR TECHNICAL EFFICIENCY OF UNIVERSITIES FOR THE ACADEMIC YEAR 2019-2020

\begin{tabular}{ccccccc}
\hline \hline S. No. & DMU(UNIVERSITY) & $\begin{array}{c}C C R T . E \\
R^{*}\end{array}$ & References & Rank & Peers & $\begin{array}{c}\text { Name of the } \\
\text { Peer University }\end{array}$ \\
\hline \hline 1 & Kakatiya University (KU) & 0.8070 & 0 & 4.5 & 1 & OU
\end{tabular}




\begin{tabular}{|c|c|c|c|c|c|c|}
\hline 2 & $\begin{array}{l}\text { Mahatma Gandhi } \\
\text { University (MGU) }\end{array}$ & 0.5440 & 0 & 4.5 & 2 & $\mathrm{OU}, \mathrm{SU}$ \\
\hline 3 & Osmania University (OU) & 1.0000 & 5 & 1 & - & $\mathrm{OU}$ \\
\hline 4 & Palamuru University (PU) & 0.8220 & 0 & 4.5 & 1 & OU \\
\hline 5 & Satavahana University (SU) & 1.0000 & 2 & 2 & - & SU \\
\hline 6 & Telangana University (TU) & 0.6080 & 0 & 4.5 & 2 & OU, SU \\
\hline
\end{tabular}

From Table II it is clear that the CCR model Technical Efficiency (TE) of the six universities has the following limits i.e., $0.544 \leq R^{*} \leq 1.00$. According to CCR model two universities have been performed well and has efficient status namely Osmania University (O.U) and Shatavahana University (S.U) and other 4 universities inputs lose as per CCR Model. Potential improvement is essential for reaming universities in order to progress his performance with regards to results.

From Table II ,we observe that Osmania University (O.U) and Shatavahana University (S.U) are performed well as per CCR Model when compared to the six universities. We observed that Osmania and Satavahana universities are peers to the remaining universities. Osmainia University O.U has five references, which is highest one in this model. The peer contributions of this university is more compare to remaining universities. According to Data Envelopment Analysis (DEA) properties every efficient DMU by its self-role model. Osmainia and Shatavahana Universities are Efficient DMUs. These two DMUS by itself is a role model DMUs. The T. E of MGU is 0.544 . Hence, M G University performance is technically inefficient frontier. If returns to scale is constant it could have produced its current outputs 0.544 or $54.40 \%$ of inputs. Thus, removal of all inefficiencies is achieved by reducing all inputs by 0.436 or $43 \%$ of their observed values. In fact, based on the reference set and peer weight, we can express the input and output values needed to bring MGU into efficient frontier. In this way we analyze the inefficient universities in order to improving their performance towards improve the results in their end examinations.

The CCR Model Distribution Score Graph is presented for the A.Y 2019-2020 as below:

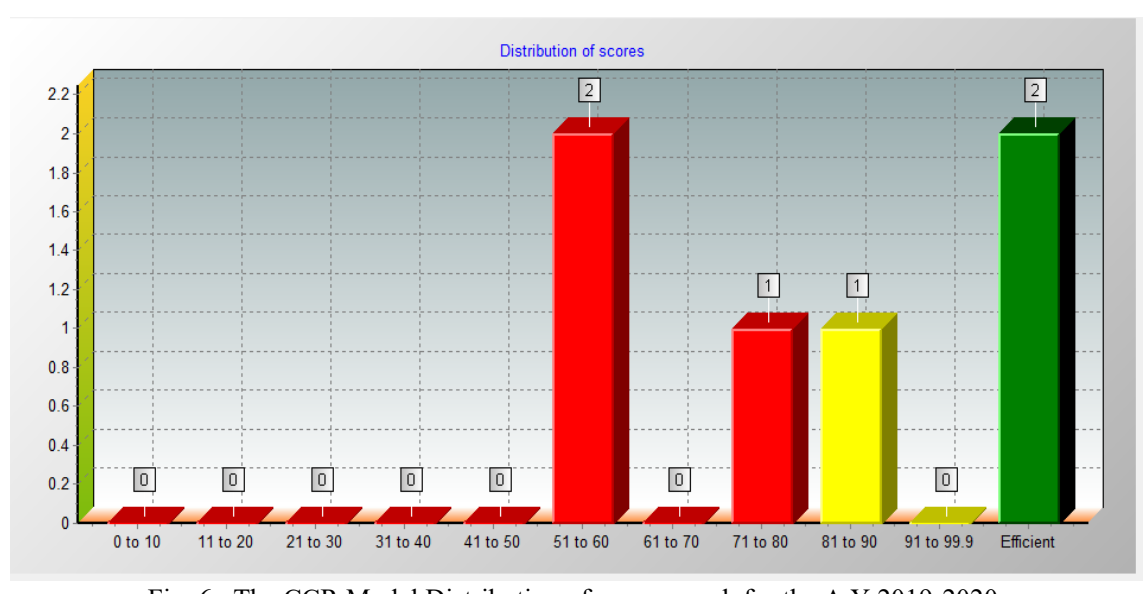

Fig. 6 . The CCR Model Distribution of scores graph for the A.Y 2019-2020.

From Fig. 6, We observe that the CCR Model distribution of scores graph 51-60: 2 DMUs, 71-80: 1 DMU ,81-90: 1 DMU were found. Theses DMUs performance is technically inefficient frontier and two DMUs are in efficient frontier.

The BCC Model results are shown in the following table:

TABLE III: PURE TECHNICAL EFFICIENCY OF UNIVERSITIES FOR THE A.Y 2019-2020

\begin{tabular}{ccccccc}
\hline \hline S. No. & DMU(UNIVERSITY) & $\begin{array}{c}C C R T . E \\
R^{*}\end{array}$ & References & Rank & Peers & $\begin{array}{c}\text { Name of the } \\
\text { Peer University }\end{array}$ \\
\hline \hline 1 & Kakatiya University (KU) & 0.8710 & 0 & 5.5 & 2 & OU, SU \\
2 & Mahatma Gandhi & 0.9020 & & & 3 & PU, SU, TU \\
3 & University (MGU) & & 0 & 5.5 & OU \\
4 & Osmania University (OU) & 1.0000 & 2 & 3 & - & PU \\
5 & Palamuru University (PU) & 1.0000 & 2 & 3 & - & SU \\
6 & Telangana University(TU) & 1.0000 & 2 & 1 & - & TU \\
\hline \hline
\end{tabular}

The Pure Technical Efficiency variation for the six universities is in the following bounds i.e., $0.871 \leq$ $\theta^{*} \leq 1$. As per BCC model four universities have been performed well and efficient DMUs namely Osmania, Palamuru, Satavahana and Telangana university. Kakatiya and M.G Universities inputs loses as per BCC model Pure Technical Efficiency (PTE). Potential improvement is required for K.U and M.G.U in order to progress his performance with regards to results.

From the above table we observed that the peers to the inefficient universities seem to be Osmania University, Satavahana University, Telangana University and Palamuru University. Satavahana University 
has highest references i.e., 3. The Peer contribution of Satavahana university is more compare to remaining universities (DMUs).

The BCC Model Distribution Score Graph is presented for the A.Y 2019-2020 as below:

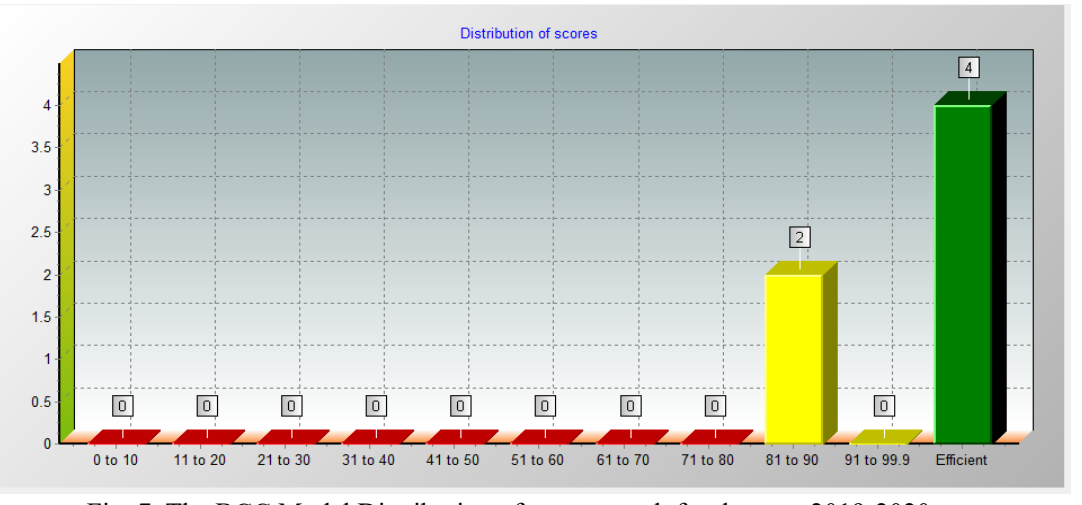

Fig. 7. The BCC Model Distribution of scores graph for the year 2019-2020.

From the above Fig. 7 it is clear that $81-90$ two universities performance is technically inefficient frontier and 4 universities (DMUs) are performing well.

The university wise Scale Efficiency and Returns to Scale and cause of inefficiency are presented below:

TABLE IV: SCALE EFFICIENCY AND RETURNS TO SCALE UNIVERSITIES FOR THE A.Y 2019-2020

\begin{tabular}{|c|c|c|c|c|c|c|c|c|}
\hline S. No. & DMU(UNIVERSITY) & CCR & $\mathrm{BCC}$ & $\mathrm{SE}$ & $\begin{array}{r}\mathrm{Cau} \\
\text { Ineff } \\
\mathrm{PT}\end{array}$ & & $\begin{array}{l}\text { Returns to } \\
\text { Scale }\end{array}$ & $\begin{array}{l}\text { Efficient/ } \\
\text { Inefficient }\end{array}$ \\
\hline 1 & Kakatiya University (KU) & 0.8070 & 0.8710 & 0.9265 & PTE & - & IRS & Inefficient \\
\hline 2 & $\begin{array}{l}\text { Mahatma Gandhi } \\
\text { University (MGU) }\end{array}$ & 0.5440 & 0.9020 & 0.6031 & - & SE & DRS & Inefficient \\
\hline 3 & Osmania University (OU) & 1.0000 & 1.0000 & 1.0000 & - & - & CRS & Efficient \\
\hline 4 & Palamuru University (PU) & 0.8220 & 1.0000 & 0.8220 & - & SE & DRS & Inefficient \\
\hline 5 & Satavahana University (SU) & 1.0000 & 1.0000 & 1.0000 & - & - & CRS & Efficient \\
\hline 6 & $\begin{array}{c}\text { Telangana University(TU) } \\
\text { Average }\end{array}$ & $\begin{array}{r}0.6080 \\
0.769\end{array}$ & $\begin{array}{c}1.0000 \\
0.962\end{array}$ & $\begin{array}{l}0.6080 \\
0.8266\end{array}$ & - & $\mathrm{SE}$ & DRS & Inefficient \\
\hline
\end{tabular}

The CCR T.E provided the efficiency evaluation using measure of scales under CRS. As per CCR model, two out of six universities are below average.

The BCC Model PTE provided efficiency evaluation using a measure of scale under VRS. As per BCC model 4 universities are efficient frontier in addition to two efficient universities in CCR Model, which retain its previous efficient frontier.

Palamuru University PU is efficiency in BCC model which is caused by its use of the smallest number of inputs even though it is the lowest in the CCR score. The BCC Model score exhibits that 2 out of 6 universities were below average.

Under the Scale Efficiency S.E exhibits 3 out of 6 universities were below average.

From the above Table IV, it clear that Osmania and Satavahana universities efficient in both models. These two universities are under Most Productive Scale Size MPSS status, while Kakatiya University shows increasing returns to scale and MGU, PU, TU shows decreasing returns to scale.

The Summary of CCR and BCC Model for the A. Y 2019-20 is presented below table:

\begin{tabular}{ccc}
\multicolumn{2}{c}{ TABLE V: SUMMARY OF CCR AND BCC MODEL } \\
\hline \hline & CCR Model & BCC Model \\
\hline Mean Efficiency & 0.796 & 0.962 \\
S.D of Efficiency & 1.9743 & 1.9049 \\
C.V of Efficiency & $40.32 \%$ & $50.50 \%$ \\
Min. Efficiency & 0.796 & 0.962 \\
Max. Efficiency & 1.000 & 1.000 \\
Number of Efficient universities & 2 & 4 \\
Total number of universities & 6 & 6 \\
\hline \hline
\end{tabular}

From the above table we observe that in CCR Model, the mean technical efficiency of six universities is 0.796, the standard deviation is 1.9743. The highest and lowest technical efficiency is 1 and 0.796 respectively and C.V is $40.32 \%$. In BCC Model the average Pure Technical efficiency of six universities is 0.962 , the standard deviation is 1.9049. The highest and lowest technical efficiency is 1 and 0.962 respectively and C.V. is $50.50 \%$. 


\section{CONCLuSiON}

From this data analysis we conclude that for the A.Y 2019-20 two universities have been emerged as efficient namely Osmainia University (O.U) and Shatavahana University. (S.U). Osmania University and Shatavahana University performance is well in CCR Model and remaining universities Potential Improvement P.I is needed for improving in their performance with regards to examination results. As per BCC model it is observed that four universities are in efficient status namely Osmania, Palamuru, Satavahana and Telangana university. Kakatiya and MG Universities inputs loses as per BCC model Pure Technical Efficiency (PTE). Osmania University (O.U) and Shatavahana Universities performs well for the both models. Under the scale efficiency we found that Kakatiya University is in IRS, M.G.U, P.U and T.U are under DRS and O.U and S.U are under CRS Status. Under Most Productive Scale Size MPSS status, while KU display increasing returns to scale and MGU, PU, TU display decreasing returns to scale. Inefficient universities in Telangana State should focus on continuous improvements in quality of education. Then their performance will be in optimal level regards their results.

\section{CONFLICT OF INTEREST}

Authors declare that they do not have any conflict of interest.

\section{REFERENCES}

[1] Rutter M. Maughan B. School effectiveness findings 1970-2002 . Journal of School Psychology. 2002; 40(6): $451-475$.

[2] Kwimbere FJ. Measuring efficiency in not-for-profit organizations: an attempt to evaluate efficiency in selected UK university departments. School of Management,University of Bath.1987.

[3] Nellutla R, Haragopal VV. Performance of Management Schools in Secondary School Examinations of Andhra Pradesh State by Data Envelopment Analysis. International Journal of Scientific Research. 2015; 4(9): 179-182.

[4] Goverdhan M, Nellutla R, Haragopal VV. A Critical Data Envelopment Analysis of Hospital efficiency in India. International Journal of Scientific Research. 2016; 5(2): 471-475.

[5] Nellutla R, Haragopal VV. Technical efficiency Management wise Schools in Secondary School Examinations of Andhra Pradesh State by CCR Model. IOSR Journal of Mathematics(IOSR-JM). 2017; 13(1): 1-8.

[6] Johnes J. Performance assessment in higher Education in Britain. European Journal of Operational Research. 1996; 2: 18-33.

[7] Pina V, Torres Y. Analyse through DEA Teaching activity of the Account Department. in Spanish Public University, 1995.

[8] Vital B, Nellutla R, Krishna Reddy M. Selection and Analysis of Input-Output Variablesusing Data Envelopment Analysis of Decision Making Units - Indian Private Sector Banks. International Journal of Engineering and Advanced Technology (IJEAT). 2021; 10(5): 119-127.

[9] Donthula P, Nellutla R, Haragopal VV. Measuring the Technical Efficiency in Agriculture Farming through CCR Model by Data Envelopment Analysis. IOSR Journal of Mathematics(IOSR-JM). 2021; 17(4): 1-10.

[10] Nellutla R, Haragopal VV. Data Envelopment Analysis of SSC Public Examinations 2009 - 2011 of Andhra Pradesh. Global Journal for Research Analysis. 2015; 4(7): 141-144.

[11] Banker RD, Charnes RF, Cooper WW. Some Models for Estimating Technical and Scale Inefficiencies in Data Envelopment Analysis. Management Science. 1984; 30: 1078-1092.

[12] Charnes A, Cooper W, Rhodes E, Measuring the Efficiency of decision making units. European Journal of Operational Research. 1978; 2: 429-444. 


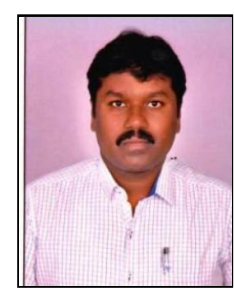

R. Nellutla, working as Associate Professor of Statistics in Department of Mathematics, Guru Nanak Institutions Technical Campus(A), Hyderabad, Telangana, India. Obtained his Master degree in M. Sc (Applied Statistics) from University College of Science, Osmania University, Hyderabad, Telangana, India. He did his $\mathrm{Ph}$. D in Statistics from Kakatiya University, Warangal, Telangana. His area of research includes Applied Statistics, Mathematical Statistics Advanced Operations Research and Data Envelopment Analysis and expertise in Data Science and SPSS. He has published 12 research papers in reputed international journals. He is an author of 16 text books, which are prescribed text books for Dr. B.R. Ambedkar Open University, Hyderabad, Telangana, India. Dr. Raju Nellutla is sessional member of ISCA. He has 17 years of teaching experience.

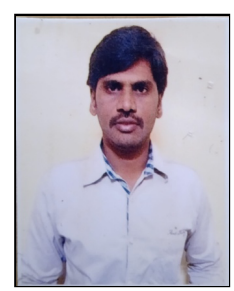

R. Ashok working as Assistant Professor of Statistics, Vishwa Vishwani Institute of Systems and Management, Hyderabad, Telangana, India. He obtained his master degree in M.Sc. (Applied Statistics) from Osmania University, Hyderabad, Telangana. Currently, He is pursing Ph.D in Statistics from Annamalai University Tamil Nadu under the Guidance of Dr. Raju Nellutla,. His area of interest is Operation Research, He has 18 years of teaching experience and expertise in Data Science, R Studio, SAS, SPSS.

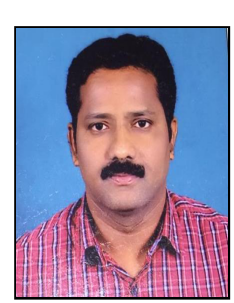

M. Ramesh, working as Assistant Professor of Mathematics, Matrusri Engineering College, Hyderabad, Telangana, India., Obtained his Master degree in M. Sc (Statistics and Mathematics) from, Osmania University, Hyderabad. He did his Ph. D from Meerut university. His area of research includes Statistics and Operations Research.

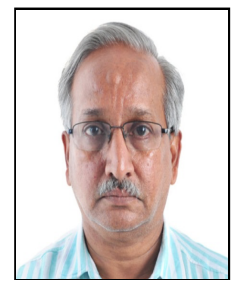

V. V Haragopal, Retired Professor of Statistics, Head and Chainman Board of Statistics and Director CQM at Osmania University, Hyderabad. He has guided around $20 \mathrm{Ph}$. D and $7 \mathrm{M}$. Phil students and published more than 100 papers in reputed international and national journals. He has delivered many invited talks across the India. Presently working as Director (AL\&ML), AiZen Algo Pvt. Ltd., Hyderabad, Telangana, India. 